Review Article

\title{
Concept of Zaght al-Dam-Qawi (Hypertension) and its Management Modalities in Unani System of Medicine
}

\author{
Mohd Abid', Sadaf Khan ${ }^{2}$, Noman Khan', Tamanna Nazli', Mohd Sajid ${ }^{4}$
}

${ }^{1}$ Research Associate, ${ }^{3}$ Research Officer, ${ }^{4}$ Technical Officer, Central Council for Research in Unani Medicine, Ministry of Ayush, Government of India, New Delhi, India.

${ }^{2}$ Research Scholar, All India Institute of Ayurveda, New Delhi, India.

DOI: https://doi.org/10.24321/2319.9113.202102

I $\quad \mathbf{N} \quad \mathbf{F} \quad \mathbf{O}$

Corresponding Author:

Mohd Abid, Central Council for Research in Unani Medicine, Ministry of Ayush, Government of India, New Delhi, India.

E-mail Id:

mabid884@gmail.com

Orcid Id:

https://orcid.org/0000-0002-1261-3117

How to cite this article:

Abid M, Khan S, Khan N, Nazli T, Sajid M. Concept of Zaght al-Dam-Qawi (Hypertension) and its Management Modalities in Unani System of Medicine. J Integ Comm Health. 2021;10(1):1116.

Date of Submission: 2021-02-02

Date of Acceptance: 2021-02-26
$\begin{array}{llllllll}\mathbf{A} & \mathbf{B} & \mathbf{S} & \mathbf{T} & \mathbf{R} & \mathbf{A} & \mathbf{C} & \mathbf{T}\end{array}$

The scope of Unani medicine is increasing day by day as people are becoming more interested in herbal and organic world. However, Unani (herbal) knowledge needs to be coupled with scientific documented research done to verify its efficacy. The aim of this paper is to provide updated knowledge on hypertension and its management in the Unani system of medicine. Hypertension is a major health hazard globally especially in developed countries. In the Unani system of medicine, there are mudirrat (diuretics) to reduce body fluids and minerals, and musakkin (relaxants) and munawwim (sedatives) are also advised by Unani physicians to reduce anxiety. Unani physician, Razi recommends venesection for this particular ailment. Unani physicians have given the concept of hypertension as "Imtila-ba-Hasb-ul-Auiya" and have said that this occurs due to sue-e-mizaj damwi and comes under the heading of Imtila. Literally 'Imtala' means gathering and fullness of the body with madda (fluids). To be precise, it means there is a buildup of normal or abnormal fluids in the body. Unani physicians were all aware of the concept of Zaghta e damwi (blood pressure). Systole as 'Zaghta-e-Inqabazi' and diastole as 'Zaghta-e-Inbesati' is well depicted in the Unani literature. Most of the world's population, mainly in developing countries, use herbal medicines for primary health care because of their ancient tradition, culture, and minor side effects. Various kinds of research have been conducted regarding the hypotensive and antihypertensive therapeutic values of local medicinal plants in the recent past, and they have provided evidence for the antihypertensive effects of some of these plants.

Keywords: Hypertension, Zaght Al-Dam-Qawi, Unani Medicine, High Blood Presure, Non Comunicable Disease, Lifestyle Disorder 


\section{Introduction}

Hypertension (HTN) or high Blood Pressure (BP) is a chronic medical condition involving the persistent elevation of $\mathrm{BP}$ in the arteries above an arbitrary limit of 130 systolic and $80 \mathrm{~mm} \mathrm{Hg}$ diastolic BP during rest. It is categorised as either primary (essential) or secondary hypertension. In approximately $90-95 \%$ of the cases, no medical cause can be found which is termed as "primary HTN" and the remaining $5-10 \%$ of cases are caused by other conditions due to the involvement of kidneys, arteries, heart, or endocrine system and is known as secondary HTN.

The condition of hypertension is characterised by Blood Pressure (BP) that is consistently $\geq 130 \mathrm{and} /$ or $\geq 80 \mathrm{~mm} \mathrm{Hg}$. However, for the majority of patients with hypertension, blood pressure varies between 130-139/ 80-89 mm Hg (stage 1 hypertension) and $\geq 140$ systolic or $\geq 90 \mathrm{~mm} \mathrm{Hg}$ diastolic (stage 2 hypertension). These categories should not be based on single BP reading but rather should be confirmed by two or more readings (averaged) made on two separate occasions. ${ }^{1}$

The clinical features demonstrating hypertension have been mentioned in Unani classical text under the heading of Imtila-ba-Hasb-ul-Auiya (repletion in regard of vessels), an increase in blood volume leading to increased vascular pressure, making the pulse hyper-volemic. In such patients, frequent epistaxis, headache, visual disturbance and rupture of blood vessels or even death may occur. Ibn-e Sina (Avicenna), an eminent physician of Unani medicine advised for husne-tadabeer (lifestyle modifications) i.e. modification in Asbaab-e sitta-e Zarooriya (six essential factors of life). ${ }^{2}$

Hypertension is the most common risk factor for NCDs burden in India. Fourth National Family Health Survey assessed hypertension in a large population-based sample $(n=799,228)$ and reported hypertension in $13.8 \%$ of men vs $8.8 \%$ of women (overall $11.3 \%$ ) aged $15-49$ years and 15-54 years respectively. 1.63 million deaths in India were caused by hypertension in 2016 as compared to 0.78 million in $1990(+108 \%)$, as per the reports of Global Burden of Diseases. The disease burden (DALYs) attributable to hypertension increased from 21 million in 1990 to 39 million in 2016 (+ 89\%). ${ }^{3}$

It is estimated that in early age the incidence is $15-20 \%$ and in the age group of 70 years or more the incidence is $75-80 \% .{ }^{4}$ According to $\mathrm{WHO}$, around 1.13 billion people have hypertension, 1 in 4 men and 1 in 5 women had hypertension in 2015. It also states that $<1$ in 5 people with hypertension have the problem under control. The World Health Organisation (WHO) estimates that high blood pressure directly or indirectly causes the deaths of at least nine million people globally every year. ${ }^{5}$
In present times, cardiovascular disease (CVD) is a major challenge for human beings. It accounts for approximately $50 \%$ of all deaths worldwide and is the leading cause of death in western and developing countries. ${ }^{6}$ Amongst, CVDs, hypertension is the leading cause of death worldwide and accounts for $13.5 \%$ of all deaths. ${ }^{7}$ Hypertension is also emerging as a major health problem in India. It accounts for two-thirds of all strokes and one-half of all ischemic heart diseases in India. ${ }^{8}$ Hypertension is one of the major risk factors for stroke, heart attack, heart failure, and kidney failure, thereby being the cause of deaths and disability worldwide. Hypertension is directly responsible for $57 \%$ of all stroke deaths and $24 \%$ of all coronary heart disease deaths. ${ }^{9}$

Primary or essential hypertension, which refers to high BP for which no medical cause can be found, constitutes $90 \%$ to $95 \%$ of cases. ${ }^{6}$ The remaining 5 to $10 \%$ of cases, come under secondary hypertension, which is known to be caused by some other conditions that affect the kidneys, arteries, heart, or endocrine system. ${ }^{10}$ Hypertension is a major public health problem due to its high prevalence all around the globe. ${ }^{6}$ Around 7.5 million deaths or $12.8 \%$ of the total of all annual deaths worldwide occur due to high blood pressure. ${ }^{7}$ It is estimated that there will be 1.56 billion adults globally with hypertension till $2025 .{ }^{11}$

As hypertension has become a real threat for mankind, and the allopathic medications used for it such as diuretics, beta-blockers, calcium channel blockers, ACE inhibitors, vasodilators, etc. cause various adverse effects like electrolyte imbalance, insomnia, bradycardia, and liver dysfunction. Therefore, the use of herbal drugs alternatively for managing hypertension mentioned in Unani literature opens new avenues to tackle this mammoth crisis.

Masih-ul Mulk Hakim Ajmal Khan in the 1920s was the first to perceive the concept of research in Unani medicine. Multitalented brilliant of his time, Hakim Ajmal Khan spotted a chemist named Dr Salimuzzaman Siddiqui for undertaking chemical studies on a few significant medicinal plants used in Unani Medicine. Dr Siddiqui materialised the vision of Masih ul Mulk. The discovery of the medicinal property of the herb Asrol (Pagalbooti), after continuous research led to the establishment of the exceptional effect of this plant known as Rauwolfia serpentine in neurovascular and nervous illnesses, such as hypertension, insanity, schizophrenia, hysteria, insomnia, and psychosomatic conditions etc. ${ }^{12}$

The ajmaline, ajmalinine, and ajmalicine compounds were first isolated by Dr. Salimuzzaman Siddiqui in 1931 from the roots of Rauwolfia serpentina. ${ }^{13}$ He named these alkaloids after Hakim Ajmal Khan, one of the most renowned practitioners of Unani medicine. 


\section{Aetiology/ Risk Factors}

\section{Primary Hypertension}

Although no obvious cause has been identified itself, there are many factors such as:

- Sedentary lifestyle

- Stress, visceral obesity

- Potassium deficiency (hypokalemia) ${ }^{8}$

- Obesity: More than $85 \%$ of cases occur in those with a BMI greater than $25^{14,15}$

- Salt (sodium) sensitivity ${ }^{16}$

- Harmful use of alcohol ${ }^{17}$

- Vitamin D deficiency ${ }^{18}$

- Ageing: Risk also increases with ageing ${ }^{19}$

- Some inherited genetic mutations ${ }^{20}$

- Having a family history ${ }^{21}$

- An elevation of rennin, an enzyme secreted by the kidney, is another contributing factor ${ }^{22}$

- Sympathetic nervous system over activity ${ }^{22}$

- Insulin resistance also contributes to hypertension ${ }^{24}$

\section{Secondary Hypertension}

Hypertension (HTN) occurs due to compromise or imbalance of the patho-physiological mechanisms, such as the hormone-regulating endocrine system, that regulates blood plasma volume and heart function. Many conditions cause HTN. Some are common and well-recognised secondary causes such as Cushing's syndrome, which is a condition where the adrenal glands overproduce the hormone cortisol. ${ }^{23}$ In addition, HTN is caused by other conditions that cause hormone changes such as hyperthyroidism, hypothyroidism, and adrenal gland cancer. Other common causes of secondary HTN include kidney diseases, obesity/ metabolic disorder, pre-eclampsia during pregnancy, the congenital defect known as coarctation of the aorta, and certain medications.

\section{Concept of Hypertension in Unani System of Medicine}

The most important cause of hypertension is Imtila-e-Dam, which is of two types:

- Imtila bi Hasb al-Aw'iya (Repletion in regard to vessels)

- Imtilabi Hasb al-Quwa (Repletion in regard to power)

In Imtila-ba-Hasb-ul-Auiya there is a rise in blood volume resulting in increased vascular pressure. Generally, Imtilaba-Hasb-ul-Auiya (repletion regarding vessels) is the condition, where an increase in the blood volume occurs, due to which the intra-arterial pressure is raised, the pulse gets hypervolemic and is hard on feel. Such patients develop the tendency of frequent epistaxis, headache, and visual disturbances and at times the rupture of vessels resulting in fatal complications. This type of Imtila is due to excessive accumulation of metabolic products, whether mahmooda (beneficial) or ghair-mahmooda (harmful), and this type of congestion is common among obese people. ${ }^{2}$

In the condition of Imtila-e-dam bahasb-ul quwa (repletion in regard to power), there is disturbance of quwwat-enafsaniya, quwwat-e-mudabbira badan and quwwat-etabia of the body. In this, the disturbance of quwwat-etabia leads to altered digestion which results in injurious byproducts. Likewise, altered quwwat-e-nafsaniya and quwwat-e-mudabbira badan also deteriorate body systems at the very minute levels, so that even a small quantity of toxic byproducts may cause symptoms of Imtila. ${ }^{14,28,32}$

An excess of food intake and alcohol, sedentary lifestyle and lack of exercise causes an increase in waste products in our body. Excess of mahmooda (normal) or ghair-mahmooda (abnormal), both lead to congestion (imtila) and are toxic for the body. This condition of imtila is commonly found in obese people. This was the view of famous Unani physicians, Ibn Sina and Majusi. One of the factors responsible for stagnation of abnormal humors at any place is weakness of arteries. ${ }^{32}$

\section{Patho-physiology}

Essentially, Blood Pressure (BP) is the outcome of cardiac output and peripheral vascular resistance $(B P=$ cardiac output $\times$ peripheral vascular resistance). Therefore, maintenance of a normal BP depends on the balance between cardiac output and peripheral vascular resistance. ${ }^{9}$

The pathogenesis of hypertension is multi-factorial and highly complex. Many factors (and risk factors) have been implicated in the genesis of essential and secondary hypertension. ${ }^{8}$

\section{Essential Hypertension}

- Increased sympathetic nervous system activity

- Increased production of sodium-retaining hormones and vasoconstrictors

- Deficiencies of vasodilators such as prostacyclin and nitric oxide

- Inappropriate or increased renin secretion, resulting in increased production of angiotensin-II and aldosterone

- Genetic predisposition

\section{Secondary Hypertension}

The common identifiable causes of hypertension are the following:

- Chronic kidney disease

- Renovascular disease

- Cushing's syndrome (hypersecretion of the hormone cortisol)

- Pheochromocytoma (adrenal tumour)

- Drugs such as non-steroidal anti-inflammatory drugs (NSAIDs) and oral contraceptive 


\section{Complications}

The complications of untreated/ uncontrolled hypertension include: $^{7}$

- Stroke

- Aortic aneurysm

- Myocardial infarction

- Congestive heart failure

- Cardiac enlargement

- Left ventricular hypertrophy

- Renal insufficiency

- Cerebral thrombosis or embolisation

\section{Management in Unani System of Medicine}

In Unani medicine, control of 'Imtila' (Hypertension) is classified into 3 groups:

\section{Ilaaj-bil-Ghiza (Dietotherapy)}

In the Unani system of medicine, there are elaborative dietary recommendations that are very beneficial for the prevention of hypertension, as the common risk factors such as hyperlipidemia and atherosclerosis, are better regulated by dietary measures. Diets containing high potassium may slightly lower blood pressure. Some Unani drugs which are considered as anti-hyperlipidemic and anxiolytic such as Kalonji (Nigela sativa), Lehsan (Allium sativum), Zeera Siyah (Carum carvi), Kishniz (Coriandrum sativum), Piyaz (Allium ceppa), and Gajar (Daucas carota) are also beneficial in hypertension. ${ }^{28}$ There are several ways in which high blood pressure can be prevented. Some of them are as follows:

- Maintain a healthy weight as per age, height and sex

- Reduce salt intake to less than $5 \mathrm{~g}$ daily

- Eating fibre rich diet with fruits and vegetables

- Cessation of tobacco use

- Reduce alcohol consumption

- Reduce intake of foods rich in saturated fats

\section{Ilaaj bil-Tadbeer (Regimental Therapy)}

Ilaaj bil-Tadbeer is the modification in Asbab-e-Sitta Zarooriya (six essential prerequisites). This mode of treatment is very effective for the prevention and control of Imtila' (hypertension). Having adequate sleep, increased physical activity, reduction of mental tension and anxiety may reduce the clinical implications of 'Imtila'. Some common regimental the rapies for the management of Imtila are Cupping (Hijamah), (venesection), Ta'leeq (leeching), Is'hal (purgation), Ta'reeq (diaphoresis). $27,28,29,33$

\section{Ilaaj bil-Dawa (Pharmacotherapy)}

Several single and compound formulations have been used in the management of Imtila', which may be useful in hypertension.

The following drugs are frequently used in the management of hypertension:

Mudirrat (Diuretic): Tukhm-e-Kharpaza (Cucumis milo Linn.), Tukhm-e-Kheyarain (Cucumis sativa), Parshiaoshan (Adiantum capillus). Compound formulations; Habbe-Mudirr, Sharbat-e-Buzoori Motadil.

Musakkinat (Sedative): Sankhaholi (Evolvulus alsinoides Linn.), Asrol (Rauwolfia serpentina), Tukhm-e-Kahu (Lactuca sativa Linn.), Gul-e-Neelofar (Nymphaea lotus). Compound formulation; Habb-e-Musakkin.

Mufattihat-e-Urooq (Vasodilator): Lahsun (Alium sativum Linn.), Chaal Arjun (Terminalia arjuna Linn.). Compound formulations; Dawa-UI-Kurkum.

Mufarrihat (Exhilarant): Abresham (Silk coccoon), Sandal Sufaid (Santalum album), Sankhaholi (Evolvulus alsinoides Linn.). Compound formulation; Dawa-ul-Misk.

Munawwimat (Hypnotic): Asrol (Rauwolfia serpentina), Ood e Saleeb (Poenia officinalis), Naremushk (Mesua ferrea). Compound formulations; Ikseer-e-Shifa, Roughane-LaboobSab'a, Roughn-e-khash'khash, Roughn-e-kahu, Roughn-e-kadoo, Asrofeen.

Mubarridat (Refrigerant): Tukhm-e-Khurfa (Portulaca oleracea Linn.), Kishneez (Coriandrum sativum Linn.), Tukhm-e-Kahu (Lactuka sativa), Gul-e-Neelofar (Nymphaea lotus). ${ }^{25,} 27,29$ Compound formulations; Qurs Tabasheer Kafoori, Sharbat-e-Nilofar.

\section{Conclusion}

Hypertension burdens the community with early mortality and disability. Moreover, its expensive treatment along with the side effects of drugs compels people to be irregular with their prescriptions. Hence, alternatives to cope up with this problem are required. Unani system of medicine provides a full regimen for the control and prevention of hypertension. Each and every regimen of the Unani system of medicine has its own benevolent effects. Thus, Unani medicine plays a pivotal role in the prevention and management of hypertension with the utmost utilisation of various therapeutic modalities mentioned in classical Unani literature.

\section{Conflict of Interest: None}

\section{References}

1. Whelton PK, Carey RM, Aronow WS, Casey DE Jr, Collins $\mathrm{KJ}$, Himmelfarb CD, DePalma SM, Gidding S, Jamerson KA, Jones DW, MacLaughlin EJ, Muntner P, Ovbiagele B, Smith SC Jr, Spencer CC, Stafford RS, Taler SJ, Thomas RJ, Williams KA Sr, Williamson JD, Wright JT Jr.2017 ACC/AHA/AAPA/ABC/ACPM/AGS/APhA/ASH/ASPC/ NMA/PCNA Guideline for the Prevention, Detection, Evaluation, and Management of High Blood Pressure in Adults: Executive Summary: A Report of the American 
College of Cardiology/American Heart Association Task Force on Clinical Practice Guidelines. Hypertension. 2018 Jun;71(6):1269-324. [PubMed]

2. Bakar RA, Murshid K. (Urdu translation). New Delhi: Taraqqi Urdu Bureau; 1996;54-6.

3. Gupta R, Gaur K, Ram CV. Emerging trends in hypertension epidemiology in India. J Hum Hypertens. 2019 Aug;33(8):575-87. [PubMed] [Google Scholar]

4. Kamath SA. API Textbook of Medicine: Hypertension and its management. 10th ed. New Delhi: Jaypee Medical Publishers and Distributors; 2015;916-20.

5. A global brief on hypertension - Report. 2013. Contract No.: WHO/DCO/WHD/2013; [cited 2021 May 29]. Available from: https://www.who.int/publications/i/ item/a-global-brief-on-hypertension-silent-killerglobal-public-health-crisis-world-health-day-2013

6. Kampoli AM, Tousoulis D, Antoniades C, Siasos G, Stefanadis C. Biomarkers of premature atherosclerosis. Trends Mol Med. 2009 Jul;15(7):323-32. [PubMed] [Google Scholar]

7. Kyrou I, Chrousos GP, Tsigos C. Stress, visceral obesity, and metabolic complications. Ann N Y Acad Sci. 2006 Nov;1083:77-110. [PubMed] [Google Scholar]

8. Carretero OA, Oparil S. Essential hypertension. Part I: Definition and etiology. Circulation. 2000 Jan 25;101(3):329-35. [PubMed] [Google Scholar]

9. Beevers G, Lip GY, O'Brien E. ABC of hypertension: The pathophysiology of hypertension. BMJ. $2001 \mathrm{Apr}$ 14;322(7291):912-6. [PubMed] [Google Scholar]

10. Ahmed A, Rahman M, Hasan R, Shima SA, Faruquee MH, Islam T, Haque SE. Hypertension and associated risk factors in some selected rural areas of Bangladesh. Int J Res Med Sci. 2014 Aug;2(3):925-31. [Google Scholar]

11. Joshi UH, Ganatra TH, Desai TR, Tirgar PR. Evaluation of antihypertensive activity of Evolvulus alsinoides in adrenalin induced hypertensive rats. Int J Pharmacy Pharma Sci. 2012;(4):194-8. [Google Scholar]

12. Center Council for Research in Unani Medicine [Internet]. A versatile genius of his time, Hakim Ajmal Khan spotted Dr. Salimuzzaman Siddiqui - a chemist for undertaking chemical studies on some important medicinal plants used in Unani Medicine; [cited 2021 May 25]. Available from: https://ccrum.res.in/ UserView/PrintContent?mid=1476.

13. Siddiqui $\mathrm{S}$, Siddiqui RH. Chemical examination of the roots of Rauwolfia serpentina Benth. J Ind Chem Soc. 1931;8:667-80.

14. Abbas MAI. kamelul Sana'at (Urdu translation by Gulam Hussain Kantoory). New Delhi: Idara Kitabush-shifa; 2010;548-51.

15. Wofford MR, Hall JE. Pathophysiology and treatment of obesity hypertension. Curr Pharm Des. 2004;10(29):3621-37. [PubMed] [Google Scholar]

16. Haslam DW, James WP. Obesity. Lancet. 2005 Oct 1;366(9492):1197-209. [PubMed]

17. Lackland DT, Egan BM. Dietary salt restriction and blood pressure in clinical trials. Curr Hypertens Rep. 2007 Aug;9(4):314-9. [PubMed] [Google Scholar]

18. Djoussé L, Mukamal KJ. Alcohol consumption and risk of hypertension: Does the type of beverage or drinking pattern matter? Rev Esp Cardiol. 2009 Jun;62(6):603-5. [PubMed] [Google Scholar]

19. Lee JH, O'Keefe JH, Bell D, Hensrud DD, Holick MF. Vitamin D deficiency an important, common, and easily treatable cardiovascular risk factor. J Am Coll Cardiol. 2008 Dec 9;52(24):1949-56. [PubMed] [Google Scholar]

20. Tuohimaa P. Vitamin D and aging. J Steroid Biochem Mol Biol. 2009 Mar;114(1-2):78-84. [PubMed] [Google Scholar]

21. Dickson ME, Sigmund CD. Genetic basis of hypertension: revisiting angiotensinogen. Hypertension. 2006 Jul;48(1):14-20. [PubMed] [Google Scholar]

22. Luma GB, Spiotta RT. Hypertension in children and adolescents. Am Fam Physician. 2006 May 1;73(9):155868. [PubMed] [Google Scholar]

23. Segura J, Ruilope LM. Obesity, essential hypertension and renin-angiotensin system. Public Health Nutr. 2007 Oct;10(10A):1151-5. [PubMed] [Google Scholar]

24. Dodt C, Wellhöner JP, Schütt M, Sayk F. Glucocorticoids and hypertension. Internist (Berl). 2009 Jan;50(1):3641. [PubMed] [Google Scholar]

25. Lakshmi T, Roy A, Durgha K, Manjusha V. Coping with hypertension using safer herbal medicine - a therapeutic review. Int J Drug Dev Res. 2011;3(3):31-57.

26. Tabassum N, Ahmad F. Role of natural herbs in the treatment of hypertension. Pharmacogn Rev. 2011 Jan;5(9):30-40. [PubMed] [Google Scholar]

27. Nisar SS. Clinical study on essential hypertension and evaluation of the efficacy of persiyoshan and Sankhahoi in its management. Department of Moalejat, Jamia Hamdard, New Delhi; 2012;58-65.

28. Jurjani AH. Zakhira Khowarezam Shahi. Part 1 (Urdu translation). Lucknow: Matba Munshi Naval Kishore; 1903;24-25.

29. Arif M. Clinical study on primary hypertension and a comparative evaluation of Qurs-e-Dawa-us-Shifa with amlodipine in its management. Department of Moalejat, Aligarh Muslim University; 2008;35-52.

30. Amraz-e- Qalbe. New Delhi: CCRUM; 1995;208-30.

31. Ibn-e-Sina. Al Qanoon Fit Tib. Urdu translation by Gulam Hussain Kantoori. New Delhi: Ejaz Publication House; 2010;136-7. 
32. Iqbal N. Concept of hypertension (Zaghtuddam Qawi) in Unani system of medicine. Intern Pharma Sciencia. 2013;3:2.

33. Aleyeidi NA, Aseri KS, Matbouli SM, Sulaiamani AA, Kobeisy SA. Effects of wet-cupping on blood pressure in hypertensive patients: a randomized controlled trial. J Integr Med. 2015 Nov;13(6):391-9. [PubMed] [Google Scholar] 